\title{
A TERCEIRA MARGEM DO RIO OIAPOQUE: COMÉRCIO E GARIMPO NA FRONTEIRA FRANCO-BRASILEIRA
}

\section{THE THIRD MARGIN OF THE OIAPOQUE RIVER: COMMERCE AND MINING IN THE BRAZILIAN- FRENCH BORDER}

\author{
Antonio Sabino da Silva Neto* \\ Leonardo Damasceno de Sá*
}

\section{Introdução}

Nas Primeiras Estórias, o escritor João Guimarães Rosa (1994, p.409-413) faz um narrador menino provocar no leitor uma inquietação profunda sobre o sentido da terceira margem do rio na qual se consome o fantasma de seu pai. Trata-se da escrita de uma condição de estranheza existencial entre as margens de um rio. Uma condição de deslocamento. Nesse texto, intitulado $A$ terceira margem do rio, a terceira margem remete a um vivente em perigo, que navega, para além do entre rios, com seus desejos, sonhos, crenças, expectativas e medos. Há uma inconstância não passível de ser contida entre as margens do rio. As instabilidades socioespaciais diante da incerteza de um ir que não implica necessariamente em um voltar põem em questão a continuidade da vida. Pode-se ir sem que se consiga voltar, afinal. Morte, vida e desespero estão entrelaçados como experiências limites da vida das pessoas e populações nas fronteiras.

Iniciamos com esse exercício de imaginação sociológica, pois neste artigo se pretende discutir a condição do garimpeiro no contexto de comércio da fronteira franco-brasileira. Uma condição que, como ve-

* Professor de Ciências Sociais da Universidade Federal do Amapá - UNIFAP - (Macapá/AP/Brasil). Doutorando em Sociologia pela Universidade Federal do Ceará. E-mail: antonio.sabinoneto@yahoo.com. ** Professor e pesquisador do Programa de Pós-Graduação em Sociologia da Universidade Federal do Ceará - UFC - (Fortaleza/CE/Brasil). Doutor em Sociologia. E-mail: leonardo_sa@uol.com.br 
remos, envolve sonhos, expectativas de realização social e, também, frustrações causadas pela dura realidade da vida na terceira margem do rio Oiapoque. A terceira margem aqui remete às dimensões simbólicas e morais dessa experiência sócio-histórica, que se confronta com as dinâmicas econômicas e políticas dos mercados e dos estados.

Partimos da observação mais geral de que há um esquema de percepção e avaliação difuso, que circula entre garimpeiros oriundos das populações nordestinas e amazônicas do Brasil, segundo o qual, por concentrar elevada quantidade de recursos naturais, a fronteira do Amapá com a Guiana Francesa seria auspiciosa, promissora e propiciadora para aqueles que desejam fazer fortuna e mudar de vida. Um traço marcante no universo de crenças social pesquisado. Para tanto, eles migraram de modo sistemático desde o início do século $\mathrm{XX}$ para as florestas franco-brasileiras em busca de metais preciosos, especialmente, em busca do ouro (ALCINO, 1970). São em sua maioria paraenses, cearenses e maranhenses que desbravam as terras fronteiriças e deflagram intenso trabalho em garimpos, sejam legais ou ilegais (SOARES; CHELALLA, 2009; ANDRADE, 2008). Entre estes trabalhadores existem aqueles que transitam diariamente entre os dois países, pois se empregam em um lado do rio e residem no outro (ANDRADE, 2008). Outros migrantes utilizam Oiapoque ${ }^{1}$, muitas vezes, como ponto de passagem para os garimpos ilegais existentes nas florestas da Guiana Francesa e do Suriname (SILVA, 2016). Guiados por este princípio de $d i$-visão, as ações práticas de nortistas e nordestinos são marcadas por uma constante apreciação de suas chances de realização da expectativa de mobilidade social ascendente.

Produzimos os dados qualitativos que embasam este artigo por meio de conversas informais, entrevistas em profundidade e pesquisa etnográfica entre 2016 e $2019^{2}$. Os dados que informam que os dois tipos de mobilidade supracitados ocorreram antes mesmo da década de 1970, envolvendo garimpeiros que vivenciaram o "fuxico do ouro" , e que, atualmente, se valem de outras atividades laborais para sobreviver.

1. Segundo o IBGE, no ano de 2017, a cidade de Oiapoque possuía 25514 habitantes, sendo 1/3 desta população de origem indigena.

2. Este artigo é resultado de uma pesquisa em desenvolvimento intitulada " 0 descer e o subir no rio: comércio e garimpo na fronteira franco-brasileira”, que se encontra em andamento desde 2016, em parceira entre a Unifap e a UFC. A partir de 2019 esta pesquisa se tornou projeto de doutorado em andamento, sendo o orientando e o orientador os co-autores deste artigo. A estratégia de obtenção dos dados focou especialmente em incursões a campo durante setembro de 2016 e janeiro de 2019; em entrevistas em profundidade realizadas com cinco interlocutores; e em uma infinidade de conversas informais na vida cotidiana do garimpo e com moradores locais das cidades que reúnem garimpeiros.

3. 0 "fuxico do ouro" é relatado entre os moradores de Oiapoque quando se referem à época em que era possível pegar uma bateia - peneira que serve como ferramenta para classificar o ouro do cascalho - e ir a margem do rio e retira-lo sem as dificuldades que existem em garimpos que utilizam explosivos. Momento de maior efervescência da atividade aurifera em Oiapoque. 
Há uma percepção social que recortada, o universo pesquisa que sustenta o relato, segundo o qual boa parte dos empreendedores aplicou seus ganhos financeiros com a garimpagem em outras atividades econômicas, enquanto outros, como contam os residentes locais, "gastaram tudo com mulheres e porres”, foram perdulários, não souberam seguir a racionalidade econômica da acumulação de capital.

Em trabalho de campo em Oiapoque, pudemos escutar narrativas biográficas que se relacionam diretamente com a migração daqueles que encontraram na fronteira franco-brasileira um local para construir suas trajetórias sociais (BOURDIEU, 1986). Além da busca por recursos materiais e financeiros, muitos permaneceram na localidade pelo destaque obtido como homens "respeitados" pela comunidade oiapoquense, feito não alcançado em suas cidades de origem, de modo que a economia econômica funciona de modo imbricado com uma economia simbólica de prestígio, honra e reputação.

Foi a partir deste contexto que Oiapoque efetivamente se caracterizou como núcleo urbano nas três últimas décadas do século XX. É importante salientar que esta frente de expansão fronteiriça foi consolidada após a criação de cinco colônias agrícolas entre os anos de 1954 e 1956 no Território do Amapá - à época recentemente fundado -, dentre as quais se destacam a Colônia Agrícola do Oiapoque e a Colônia Agrícola Vila Velha do Cassiporé (ANDRADE, 2008).

Vila Velha do Cassiporé atualmente é um distrito da cidade de Oiapoque, localizado próximo à estrada do Garimpo do Lourenço, o mais antigo em atividade no Brasil e que no último ano enfrentou uma operação da Polícia Federal contra o contrabando de ouro. Foram presos im- portantes políticos amapaenses suspeitos de envolvimento com o tráfico internacional aurífero, o que deu uma visibilidade pública maior para o problema social do tráfico.

Pela grande quantidade de migrantes que vem sendo contabilizada desde a década de 1950 (ALCINO, 1970; ANDRADE, 2008; SILVA, 2014; SILVA, 2016), alguns garimpeiros afastaram-se das áreas próximas ao centro da cidade, objetivando novos mercados com menor concorrência. Encontraram, ao subir o rio Oiapoque, uma aldeia de índios Wãpi, atual cidade de Camopi, sobre a qual existem relatos de sua existência anteriores aos anos 30 do século passado (PALHARES, 2016, p. 114).

Nesta aldeia, no lado pertencente ao território brasileiro, foi construída uma comunidade cujo nome é Vila Brasil. Formada em sua maioria por garimpeiros-comerciantes, relatos informam que esta passou a dar suporte aqueles que seguiam para os garimpos ilegais existentes tanto no território brasileiro como também em território internacional, tendo servido de apoio, muitas vezes, para pessoas que seguiam para garimpos até na Venezuela (SOARES; CHELALA, 2009; SILVA, 2016). Desde 2002, a referida comunidade está cravada dentro do Parque Nacional Montanhas do Tumucumaque, o que gera intensos conflitos quanto a sua manutenção, tendo em vista que a moradia humana não é permitida nos parques nacionais brasileiros (SILVA NETO; LANDIM NETO, 2017).

Por isso, na contextualização do objeto deste artigo, discutimos sobre as relações que envolvem mobilidade, trabalho, comércio e meio ambiente, vivenciadas por garimpeiros e ex-garimpeiros na cidade de Oiapoque e no distrito de Vila Brasil, que fazem fronteira respectivamente com as ci- 
dades francesas de São Jorge de Oiapoque e de Camopi ${ }^{4}$.

Perceber que estas quatro demandas, que envolvem problematizações culturais, sociais, econômicas e ecológicas estão estritamente vinculadas para o entendimento sobre os processos de criação de sociabilidades nas fronteiras como elementos explicativos de uma configuração mais ampla (OLIVEIRA FILHO, 1979) constitui-se como marcadores do percurso deste trabalho. Como exemplo específico das questões indicadas, analisamos, de modo sintético, na última sessão deste artigo, a história de vida de dois agentes sociais que vieram à fronteira franco-brasileira ainda jovens em busca de construir suas trajetórias através da garimpagem.

\section{Estudos de Fronteira}

Queremos inicialmente afirmar que, para além da ordem social concreta, há na fronteira uma dimensão imaginária, mesmo quando estamos lidando com questões materiais bem concretas, como soe ser o comércio de ouro. Em busca do ouro, as pessoas mergulham em zonas de invisibilidade e, por vezes, de morte social, arriscam tudo, tornam-se vultos na penumbra do Estado-nação. Vivem transnacionalmente, como que perdidos nos confins do mundo, onde a própria concepção do sentido a seguir, com suas determinações assoladas por uma profunda indeterminação quanto ao destino, passa ao primeiro plano (MAR-
TINS, 2014).

São os agenciamentos de crença e desejo que parecem operar com fronteiras socioespaciais em zonas indiscerníveis marcadas por relatos em disputa e multivocalidade (BECKER, 2009), à semelhança do modo como Paiva (2015) discute as falas de violência na tríplice fronteira amazônica, enfatizando a pluralidade de modos de contar histórias sobre o regime de violência na fronteira, expressando assim moralidades em fluxos dessa realidade de misturas e diferenças socioculturais. $\mathrm{Ou}$ ainda como expõem Aquino e Vargas (2016), os dilemas da criminalidade e da segurança pública que assolam a fronteira franco-brasileira, também numa chave que explora esse universo de múltiplas realidades.

Entre rios, na vadiação do ir e vir incessante entre duas margens de cada rio, habitando o largo, movendo-se para o perto e para o longe de uma ou outra das beiras, entranhadas em sua vida ribeirinha improvisada, faz com que os agentes sociais estejam existindo na indecisão que inaugura a incerteza do intervalo das trocas culturais e sociais como o momento estratégico por excelência (BOURDIEU, 1996), no qual "uma reciprocidade de perspectivas sobre um real em si indefinível” (LEFORT, 1979) opera como o ponto de partida de uma análise social situada no lugar, como lugar de pertencimentos da pessoa e de suas parcerias e desavenças, mas também de suas perdas, privações simbólicas e sofrimentos sociais (BOURDIEU, 2008), tudo remetendo,

4. São Jorge de Oiapoque, juntamente com Camopi, são duas comunas francesas que fazem fronteira com a cidade brasileira de Oiapoque - AP. 
portanto, à pequena miséria que marca a condição de vida na fronteira. Entre realizações fugazes e desrealizações que expõem a precariedade dos arranjos cotidianos para lidar com a impermanência das relações sociais. E, neste sentido, a fronteira precisa ser pensada como um "limiar ativo" (SENNETT, 2015, p.253), uma forma múltipla de controle socioespacial que vai além das divisas que enquadram de modo representacional as relações entre comunidades em condições fronteiriças.

De migrações entre regiões, tornam-se migrantes entre as margens de uma fronteira que encerra ambição e desilusão, alguma fortuna por vezes, mas que encerra as formas de uma experiência social bastante fluida e instável. A variação incessante no meio do rio parece animar o próprio princípio da espacialização coletiva na fronteira. Ir-se e não voltar, ou então sem nunca ir e voltar de parte nenhuma das partes do conhecível e nem mesmo do não encontrável, que, afınal, é onde há outras partes conhecíveis, apesar de longínquas.

A noção de fronteira é heuristicamente mobilizada para que se possa explorar as falas e os relatos dos agentes sociais que vivem e se arriscam na fronteira franco-brasileira, cujas vicissitudes formam o escopo substantivo do esforço descritivo e analítico que aqui se intenta. Refletir sobre a categoria fronteira se constitui como ação fundamental para se entender como se processam as relações sociais existentes na linha lindeira amapaense, sobretudo ao ter Oiapoque e seus vizinhos como corte espacial. As problematizações sobre a construção da fronteira, tanto como espaço social, como ferramenta metodológica, nos sugeriram buscar correntes de interpretação sobre as multiplicidades do real observadas sobre as concepções do referido fenômeno, o que nos faz buscar como fragmentos, detalhes e alguns pontos que parecem naturais podem ser reveladores desse mosaico a ser montado.

Nesta perspectiva, nos inspiram alguns autores, cujas reflexões sobre a formação da fronteira nacional no Brasil puderam ser pensadas no contexto de engendramento do próprio quadro mental do problema a ser analisado, como eles fizeram análises vinculadas ao que se denomina nos estudos de fronteira como "frentes de expansão”. Portanto, como aponta José de Sousa Martins (2009), a fronteira pode designar os limites territoriais entre dois países, como também se constitui como local de encontros e desencontros socioculturais, ao promover novas configurações sociais.

Assim como Martins (2009), Otávio Velho (1972) preocupou-se em estudar as incursões produzidas sobre áreas que propiciavam o afastamento de parte da população campesina que não vislumbrava a cidade e o trabalho em fábricas como alternativa de subsistência. As terras ainda não desbravadas no Brasil surgiram como local propício para a nova construção de trajetórias sociais, propiciadas por uma percepção do menor controle do Estado sobre as práticas dos moradores que lá residiam. Pois se o processo foi induzido no contexto de um Estado de um capitalismo autoritário, torna-se um certo paroxismo alimentar tal percepção de menor controle. Mas esta é uma pista que não iremos desenvolver em todas as suas consequências neste texto.

É válido destacar que a produção nacional esteve diretamente influenciada pelo debate sobre fronteiras a partir da contribuição de Max Weber (1994), autor que se dedicou a compreender como a construção dos Estados modernos se tornou fundamental para entender a formação de um 
país a partir das demandas provenientes de uma estreita ligação entre seus membros, alicerçada na pretensão do monopólio legítimo da violência e do fisco, o que faz da fronteira uma questão de Estado. Nas comunidades políticas, as concepções de território e de fronteira surgem como norteadoras do debate clássico sobre o problema aqui discutido. Em Weber, a comunidade política está ligada à sua consolidação num dado território, numa espacialização das relações sociais, no qual o respeito às leis, como meio específico, constitui fator preponderante da legitimidade e da crença legitimadora da dominação social mantida por esse tipo de associação.

Porém, pensar a formação de uma fronteira, como apontam Paiva (2016) e Albuquerque (2009), num registro mais próximo de nosso objeto de pesquisa, vai além de designar os limites de um país, tendo em vista que é necessário entender as imbricações culturais, sociais e econômicas que fundamentam a fomentação de uma comunidade política, como aqui pretendemos problematizar.

\section{Vias de mobilidade no trânsito, vias de mobilidade social}

Esta sessão discute os caminhos utilizados por percursos de agentes sociais que têm a fronteira franco-brasileira como ponto de chegada ou ponto de partida de seus trânsitos e mobilidades. Especificamente, apontamos o engendramento de sociabilidades fronteiriças, alicerçadas em moralidades compartilhadas socialmente durante os percursos entre as vias de acesso à fronteira, o que envolve zonas de escuro-claro, de indiscernibilidade entre legal e ilegal. Não obstante, ressaltamos que os itinerários percorridos através das estradas e dos rios, interligados ou divididos por pontes, caracterizam-se como percursos difíceis de serem interpretados devido às intempéries e dificuldades no processo de deslocamento na fronteira que dificulta uma visão geral, uma visão do todo, pois o próprio fenômeno possui uma característica de socialidade centrífuga.

Inseridos neste emaranhado das possibilidades de fluxos, as terminologias "difícil" ou "dificuldade" são categorias que nos ajudam a problematizar os locais de fala no campo de pesquisa. Utilizadas por viajantes quando se referem à viagem ao Oiapoque, são acionadas por funcionários públicos, garimpeiros, comerciantes, pirateiros ${ }^{5}$, turistas e outras pessoas que utilizam a BR156 com o objetivo de chegar à fronteira com a Guiana Francesa. A via liga a cidade de Laranjal do Jarí, sul do estado, ao seu extremo norte, o município de Oiapoque, perfazendo cerca de $900 \mathrm{KM}$; destes, mais de 350 KM não se encontram asfaltados sendo $110 \mathrm{KM}$ entre as cidades de Macapá e de Oiapoque (SILVA, 2014).

Como aponta Rabossi (2015), nas fronteiras há a formulação de um vocabulário

5. Os pirateiros são taxistas que realizam transporte de pessoas e de mercadorias entre as cidades de Macapá e de Oiapoque em veículos 4x4, costumeiramente Hilux. Seus serviços são utilizados principalmente no período chuvoso, denominado pela população como "inverno amazônico", momento em que a utilização de ônibus e de pequenos carros é quase impraticável para viajar na estrada entre Macapá e Oiapoque. 
que tipifica e promove contatos, vendas e outros dispositivos de interação entre os agentes. Essas terminologias são mobilizadas para se referir às condições de tráfego da "estrada", assunto corriqueiro entre os moradores do município que necessitam realizar o translado regularmente. Perguntar-se sobre ter notícias da estrada é central, "tem notícias da estrada?" ou "como vai a estrada?”, afınal, são questionamentos frequentes para o universo dos conhecimentos práticos dos agentes sociais implicados em conversas entre conhecidos ou desconhecidos sobre suas experiências em comum. Percebendo isso, muitas vezes estas perguntas foram utilizadas como estratégia para proporcionar diálogos em campo, pois os viajantes se estimulam em conversas quando relatam as principais dificuldades e aventuras em suas viagens. Buscamos nos imiscuir em tais conversações como estratégia de campo.

Como exemplos de resposta, obtivemos principalmente no período de chuvas, concentradas especialmente no primeiro semestre do ano, afırmações que tangenciam as seguintes: "está difícil, quebrou uma ponte" ou "está muito dificultoso, têm três ou quatro pontos de atoleiro". Frisamos que a terminologia, em seu leque de possibilidades, não se restringe apenas ao uso específico da estrada, mas é acionada como mecanismo de possibilidades de interação que partem de contextos próprios vivenciados por migrantes que utilizam a referida via. Deste modo, buscando um sentido próprio utilizado por um grupo específico, pudemos observar o modo dos pirateiros utilizarem tais vocabulários.

Lembre-se que as condições de tráfego da BR-156 dificultam traslados rotineiros, mas movimentam a economia local, que gira em torno de várias demandas provenientes da mobilidade. Se por um lado a "estrada de barro" dificulta a passagem de pessoas e mercadorias, por outro, também dificulta a inspeção e a vigilância do transporte de pessoas, de ouro e de armas na fronteira. 0 que restringe é também o que propicia, sob aspectos diferentes.

Ademais, se a estrada gera algum prejuízo financeiro para uma parcela da população local, que paga mais caro para obter acesso a bens e serviços, outra parcela ganha com a manutenção destas condições de tráfego, cobrando valores mais elevados pelo serviço prestado. As dificuldades estimulam os lucros. Exemplo das demandas de mobilidade que são apresentadas está na seguinte afırmativa proferida por um pirateiro, quando questionado sobre as condições da estrada:

Está difícil de passar. Começou a chuva cedo esse ano. 0 diesel subiu muito. Por isso o preço da passagem que tava 150 reais na semana passada hoje tá 300. Na Semana Santa vai pra mais caro. Tem que ser motorista bom, só profissional. Não vá nesse seu carrinho pequeno não, porque se não o senhor fica no caminho. Na Tucai $^{8}$ só Hilux. Puxei dois $4 \times 4$ essa vez do governo porque os motoristas não conhecem a estrada. Tá difícil, tem que ser profissional. (Conversa com um pirateiro, em março de 2017).

6. A Tucai é uma das muitas aldeias indígenas que se localizam as margens da BR-156. Nesta aldeia, no período de chuvas, encontra-se um dos principais pontos de atoleiro. 
Para os pirateiros, a dificuldade de atravessar a BR-156 se transforma em oportunidade de subsistência e de ascensão social. Em suas histórias de vida, muitos vieram ao Oiapoque em busca de ouro, mas, após conseguir constituir um pequeno patrimônio, compraram carros para realizar o referido translado. A ascensão social destes trabalhadores envolve condições de trabalho que podem ser classificadas de autoexploração relativa face à que ocorria no garimpo, pois, quando, por exemplo, um pirateiro afirma "saí do sol do garimpo pra trabalhar no que é meu, no meu carro e no ar-condicionado" como também consideram que o sua função social é de elevada importância para a cidade, tendo em vista que "a gente recebe ligação de todo mundo, é do juiz, é do promotor, é vereador, é PF, todo mundo liga pra ir com a gente".

A inserção do pirateiro numa rede de comunicação que alimenta mais prestígio proporciona a muitos ex-garimpeiros nessa atividade, segundo suas falas, contato com "autoridades" e "pessoas importantes" que necessitam de seus serviços para chegar ao Oiapoque e exercer seus trabalhos. Tornam-se mediadores entre autoridades e população local. Muitas “autoridades” escolhem o mesmo pirateiro para viajar, inserindo dispositivos de distinção entre os próprios pirateiros, principalmente quando estes mensuram a relevância social daqueles que sempre transportam. Essa fidelização possui um alto valor político no contexto estudado. Nos percursos realizados, os pirateiros se destacam como mediadores dos vários perfis que transitam pela fronteira, possibilitando em seus veículos contato com pessoas de diferentes níveis de poder aquisitivo, origem social e escolaridade. Põem em contato elementos heterogêneos do universo em trânsito.
No sistema de práticas de conduta praticadas pelos pirateiros, há algumas regras mais ou menos difusas que devem ser observadas. A primeira regra define que não se pode recusar nenhum passageiro em viagens, e a segunda destaca, principalmente, que as relações produzidas na estrada são levadas em consideração para a criação de laços de reciprocidade entre os motoristas. Aquele pirateiro que "tem a fama" de excluir ou não comparecer para buscar um passageiro não é indicado entre seus pares quando estes atingem a lotação de seus carros, como também os pirateiros não “consideram" motoristas que não "ajudam" ou não possuem "consideração" nas relações de reciprocidade em atoleiros ou em outras dificuldades na estrada. Salientamos que a estrada não é para os pirateiros apenas um local de passagem. Nela, são acionados momentos de trocas de ajuda e de ressignificação de amizades, consideradas de elevada importância entre os profissionais, pois todos já enfrentaram problemas para chegar aos seus destinos e ter amigos é um capital social considerável.

Como descrito, a estrada entre Macapá e Oiapoque é parte do percurso de muitos funcionários públicos que foram destacados por órgãos governamentais para exercer a função de representantes do Estado na fronteira e que utilizam os pirateiros para a realização do translado. Contudo, outros migrantes, com objetivos distintos aos dos representantes do Estado e que almejam chegar à fronteira franco-brasileira com o objetivo de atravessá-la, também necessitam enfrentar este trajeto junto aos pirateiros.

É possível identificar muitos percursos nacionais ou internacionais que integram a referida fronteira como parte de seus fluxos de mobilidade, não apenas como ponto de 
chegada. Uma destas rotas é realizada por considerável contingente de migrantes que saem de seus países e entram no Brasil via terrestre, ou até mesmo por via aérea. No Brasil, chegam ao Amapá por avião ou de barco, e atravessam para a comuna de São Jorge pela cidade de Oiapoque, muitas vezes de maneira ilegal.

Em grande parte, o objetivo é chegar à Europa, e observam a Guiana Francesa como território mais propício para alcançar este intento, tendo em vista que o departamento ultramarino francês é integrante da União Europeia. Outros, muitas vezes brasileiros, se mudam para a Guiana Francesa para "ganhar em Euro", e continuam com seus laços familiares e muitas vezes residenciais no Brasil, trabalhando, por exemplo, como pedreiro ou em outros trabalhos que necessitam de força física e baixa qualifıcação para a execução. Um terceiro grupo, como salientado, migra para a fronteira em busca de trabalho nos garimpos ilegais em território internacional.

Quando em Oiapoque, é possível atravessar para o território francês pelo rio, como também pela Ponte Binacional. Esta ponte é um equipamento relativamente novo, liberado para o fluxo de carros apenas em 2017. Em São Jorge de Oiapoque, existe uma via através da qual é possível chegar a Caiena e a Paramaribo, respectivamente capitais da Guiana Francesa e do Suriname. Porém, no discurso dos oiapoquenses, a Ponte Binacional representa o marco da segregação situacional vivenciada entre os brasileiros e os franceses, pois não há bilateralidade garantida.

Ao invés de promover uma aproximação entre os dois países, a maioria dos brasileiros não utiliza o referido equipamento pela quantidade de exigências para adentrar ao território guianense, a exemplo do passaporte, do visto e do seguro internacional de vida, além do seguro para o veículo automotor. Para os habitantes do território francês, não existe nenhum impeditivo para a utilização do equipamento criado pelo governo brasileiro, tendo os cidadãos estrangeiros acesso livre a Oiapoque. Por conta desta relação permeada de múltiplos conflitos, muitos moradores de Oiapoque rechaçam a denominação de "cidade gêmea” com São Jorge.

Por conta desses fatores, a Ponte Binacional não é comumente utilizada por migrantes ilegais para atravessar a fronteira, pois é bastante vigiada. Quando viajam aos garimpos, os migrantes buscam a vastidão da floresta para adentrar e transitar em um território que, segundo garimpeiros, muitas vezes não se sabe a que país pertence; essa indecisão, inclusive, nos motivou a usar o título A terceira margem do rio Oiapoque, inspirando-nos em João Rosa. Pois, em conversas informais, quando indagados, migrantes ilegais se tornam garimpeiros, mas que ainda não constituíram laços de confiança com os pesquisadores: sempre afırmam que estão "visitando um parente" ou "de férias". Afırmar que estão em busca de trabalho na fronteira pode indicar para os órgãos de fiscalização e controle a tentativa de ingressar na atividade aurífera. São diversas as estratégias de despiste em torno da fachada social desses agentes sociais.

Para aqueles migrantes que objetivam o trabalho nos garimpos no Brasil e na Guiana Francesa, muitas vezes chegar à Vila Brasil e, principalmente, à Ilha Bela, é a primeira parte do trajeto que se impõe e se torna almejável. Só é possível viajar às localidades através do rio Oiapoque, sendo necessário percorrer das sedes dos municípios de São Jorge ou de Oiapoque um trecho de mais de $100 \mathrm{KM}$ em águas repletas 
de rochas e corredeiras, perfazendo seis horas numa canoa de metal movida a motor de combustão, conhecida entre os habitantes locais como voadeira. No percurso, ladeado por uma selva fechada, em meio às árvores de mais de 30 metros, avistamos pequenas "entradas" na mata, identificadas pelo piloto da embarcação que nos transporta como "caminho pra garimpo". Nos garimpos transfronteiriços, intensas redes de agentes sociais movimentam o fluxo das relações comerciais locais, que, como apontam Aquino e Vargas (2016), acionam políticos e joalherias de várias partes do estado do Amapá e do país. Vê-se um jogo de escalas entre micro e macro, entre local e nacional, que convida ao aprofundamento de tais análises.

\section{As fronteiras entre o trabalho e o comércio no garimpo}

Ao buscar entender as relações microssociológicas produzidas no contexto de extração do ouro, se destacam as redes de relações de poder no garimpo, caracterizadas por dominar os processos de socialização para além do dinheiro em si, mas correlacionando-o ao desejo social de reconhecimento. Nesse processo de socialização, as fronteiras assumem contextos que ultrapassam a formação específica de um Estado-nação. Apontamos percursos transnacionais que envolvem a formalidade e a informalidade do trabalho nos garimpos ilegais, além do percurso de precificação de materiais para garimpo. Torna-se então importante a tipifıcação realizada pelos próprios garimpeiros sobre a formação dos próprios garimpos, na qual destacamos como eles os classificam de modo prático.

Observamos que, nestes espaços, a moeda para a troca de comida e de outros ma- teriais utilizados para a subsistência é o grama do ouro. Neste sentido, a economia do garimpo (ROMANI, 2011) envolve vários serviços e profıssionais, não apenas o garimpeiro. Exemplo são os profissionais que vendem comida e bebida nos garimpos, chamados de marreteiros, alusão feita pelos altos preços praticados em suas vendas. Os marreteiros levam de Oiapoque aos garimpos especiarias e víveres como feijão, arroz, cerveja, cachaça, farinha, entre outros. 0 preço pago por tais produtos é destoante dos valores já elevados comumente praticados nos comércios de Oiapoque. Em conversa com um marreteiro, fomos informados quais são os principais produtos vendidos, como também os valores cobrados pelo comerciante:

Olha, meus preço são bacana. Reclama, mas ninguém faz o que eu faço. São tudo com medo da polícia do lado de lá. Num fardo de feijão de $12 \mathrm{~kg}$ eu cobro mais ou menos entre doze e quinze grama de ouro. Um fardo de latinha (doze cervejas em lata) eu vendo de três ou quatro grama de ouro. Doze quilos de arroz pode variar entre sete e nove grama. Agora quem (referindo-se às prostitutas) cobra caro mesmo pelo serviço (risos), cobra quinze grama.

Para os marreteiros, o preço é calculado segundo a distância percorrida do centro de Oiapoque para o garimpo. Contudo, não é levado em consideração apenas o valor do investimento financeiro - o combustível da voadeira, por exemplo - para atribuir o preço aos materiais vendidos. Os principais investimentos envolvidos, segundo os agentes sociais, se referem a questões como o "perigo" existente para chegar ao garimpo, como também ao "risco" de ser preso ou ter os bens confiscados pela polícia francesa. 
Assim, como na extração aurífera realizada pelos garimpeiros, ser marreteiro também é lidar com a sorte, pois segundo as palavras do entrevistado é possível "chegar com o bolso cheio de dinheiro, como também perder tudo". Estamos num universo que realiza cotidianamente suas representações sobre as chances subjetivas e objetivas de ganhos e perdas simbólicos e materiais.

Grande parte das vendas dos marreteiros é feita aos "donos do garimpo", proprietários das máquinas para extração do ouro, que são responsáveis pela disponibilização de moradia e alimentação para os garimpeiros. Como identificado por Aquino e Vargas (2016), a moradia é, em sua maioria, constituída por lonas improvisadas armadas em uma clareira aberta para abrigar pessoas e máquinas nas proximidades do local da extração. Isto ocorre porque nos pequenos garimpos ilegais da Guiana Francesa existe uma grande mobilidade nos locais de extração, tanto pelas incursões da polícia local nos pontos já conhecidos mata adentro, como também pela escassez do minério após um período prolongado de extração. Não obstante, o material e a alimentação são disponibilizados somente para aqueles que "produzem", sendo os enfermos, a exemplo daqueles picados por cobra ou que contraíram malária, enviados aos hospitais de Camopi ou de Oiapoque, cobrando-se do doente entre doze e quinze gramas de ouro pelo translado.

Os agentes sociais consideram ser produtivo num garimpo a mescla de dois fatores. 0 primeiro o trabalho com jornada de pelo menos doze horas; o segundo é a "sorte de procurar no canto certo". Costumeiramente, os garimpeiros se esforçam para que sua semana "seja boa”, exigindose uma meta mínima em torno de dez gramas de ouro para si. Em relatos obtidos em nossa pesquisa, que convergem com outros apresentados por Aquino e Vargas (2016), a divisão do ouro acontece diariamente entre os funcionários e os donos de máquina, representados por gerentes, logo após a pesagem. Em cada máquina, trabalham em média quatro garimpeiros, sendo dividido entre estes algo em torno de 30\% do total apurado. Os demais 70\% ficam em poder do dono do garimpo como lucro e manutenção do investimento.

Para os garimpeiros, nem todos os garimpos são iguais. Existe uma diferenciação local de categorizações entre os "garimpos de amigos ou garimpos de família" e "outros não muito legais, ou desconhecidos”. Nos "garimpos de família”, há redes de primos, irmãos e amigos que construíram laços sociais a partir de relações preexistentes ao garimpo. É válido salientar que esta formação "familiar” só foi construída após as primeiras incursões de migrantes, advindos principalmente do Norte e do Nordeste brasileiros, forjada através das gerações de filhos, sobrinhos e netos de antigos garimpeiros. Os demais garimpos são formados por pessoas que não possuíam vínculos anteriores à chegada naquelas paragens, dos rincões da Floresta Amazônica, e que não partilham, muitas vezes, de valores sociais em comum para além do comércio no sentido mais direto.

\section{A transição entre o ouro e o euro no comércio fronteiriço}

Neste tópico, abordamos como o Euro e o ouro impactam nas relações fronteiriças, ao demonstrar o processo de mudança nas práticas comerciais entre os habitantes fronteiriços. Destacamos uma mudança nos processos de sociabilidades local, sobretudo pela importância que se atribui ao comér- 
cio fronteiriço com o objetivo de oferecer bens e serviços na fronteira para aqueles que possuem o Euro como moeda, modificando o perfil do comércio exercido exclusivamente para o ouro.

Apontamos que este movimento duplo que atribui importância ao ouro e ao euro está em processo de consolidação. Destacamos que até o início dos anos 2000, 0iapoque não se diferenciava das currutelas de garimpo quanto à importância do ouro como mecanismo de atribuição de valor de troca entre as mercadorias, tendo em vista que a moeda corrente na cidade era quase que exclusivamente o referido metal. Atualmente, outras formas de socialização no mercado das trocas simbólicas e materiais são acionadas para além do ouro, apresentando-se como novo mecanismo de geração de riqueza local em sentido social e financeiro. As recentes configurações que se apresentam no comércio de Oiapoque assemelham-se ao disposto por Albuquerque e Paiva (2015), quando analisam uma tríplice fronteira que enfrenta movimentos similares de negociatas e transações. Como apontam os autores, os fluxos produzidos engendram novos entrelaçamentos cotidianos e mesmo que "sejam destituídas de legalidade, não são destituídas de princípios e valores que organizam as relações entre quem produz, vende e compra" (ALBUQUERQUE; PAIVA, 2015, p. 125).

Destarte, há também a mobilização da moeda nacional brasileira, o Real. Nos comércios locais, qualquer pessoa pode adquirir produtos, a exemplo do abastecimento de combustível num carro, o serviço de cortar o cabelo, como também comprar um lanche com o Euro. Portanto, saber a cotação Euro/Real como também o valor do grama do ouro é uma prática comum, fundamental entre muitos comerciantes fronteiriços, tendo em vista que o referido câmbio é realizado por grande parte dos vendedores e dos compradores em suas negociatas. Os preços podem se situar próximos aos praticados nas casas de câmbio e nas joalherias no Brasil, por vezes com tendência para um menor valor objetivando torná-los atrativos aos compradores. Quando um garimpeiro vende seu ouro às joalheiras brasileiras, o valor do grama varia entre $R \$ 80,00$ e $R \$ 110,00$, levando-se em consideração a qualidade do minério.

Além disso, não apenas o dinheiro em espécie ou o ouro são preponderantes no mercado de trocas de bens. As negociatas adquirem características pessoais, em que a origem (nacionalidade) do comprador, sua aparência e o idioma servem para mapear o perfil e consequentemente o preço do produto. Não é incomum mulheres ou homens brancos e loiros, percebidos segundo o modelo dominante euroamericano, serem cumprimentados em lojas e restaurantes por vendedores e por garçons com um "bonjour" e posteriormente obterem a informação do preço do vestuário ou do prato que estão olhando em Euro. Muitas vezes, estes mapas mentais de categorização utilizados pelos oiapoquenses não condizem com o perfil de comprador desejado, tendo em vista que muitos brasileiros de outros estados podem se assemelhar ao que estes comerciantes compreendem como um "europeu”, sendo notória a frustração de um grupo de vendedores quando observa que seu cliente é brasileiro e fala o português, o que remete a intricadas questões de etnicidade e poder na fronteira.

Porém, a percepção sobre o perfil do estrangeiro que vai realizar compras na cidade de Oiapoque fica cada vez distante de um modelo europeu idealizado pelos agentes sociais locais. 0 comércio local preci- 
sa investir cada vez mais no brasileiro que vive "do outro lado e ganha em Euro", sendo a referida moeda uma das novas esperanças de manutenção da cidade de Oiapoque, após o fim do "fuxico do ouro". Como aponta Rabossi (2015), as multiplicidades de mudanças de contexto locais partem de questões específicas do universo categorial em análise, ademais:

0 fato de o movimento ocorrer precisamente em função da existência da fronteira. Contudo, isto não se deve à mera existência da fronteira, mas à sedimentação de diversos processos históricos que tornaram possível a existência de um lugar com as características singulares (RABOSSI, 2015, p.145).

Os conflitos relativos ao comércio e à influência do ouro e do Euro na economia local não se apresentam apenas no centro da cidade de Oiapoque. 0 distrito de Vila Brasil, identificado pelos moradores do Centro de Oiapoque como a principal fornecedora de comida e materiais para a garimpagem, enfrenta longo processo de debate público informal sobre a influência do ouro e do Euro em sua economia. Os habitantes do distrito tentam se desvencilhar da percepção de que são garimpeiros, afırmando que Vila Brasil é fundamental para a existência da "cidade", tendo em vista que as suas relações comerciais são efetivamente realizadas com Camopi. Ao passo que os comerciantes do distrito não reconhecem como legítimo o trabalho dos marreteiros, pois “não pagam impostos e ainda querem vender em Camopi mais barato". Assim, o ouro e o Euro surgem atualmente como norteadores econômicos das práticas sociais fronteiriças, incutindo novos significados às trocas monetárias e reorganizando as relações de trabalho, atuando como moedas simbólicas que organizam as atividades cotidianas da região.

\section{Vila Brasil: conflitos e reciprocidades}

Para entender melhor o contexto situacional em que Vila Brasil está inserida, cuja formulação envolve múltiplos agentes, destacamos a fala de uma moradora do distrito:

0 Parque não foi criado em 2002, foi em 2006, quando chegaram aqui o Exército e o Bope armados colocaram estas placas nas nossas casas e disseram que não podíamos mais plantar, construir casas, nem nada mais porque a partir dali tudo era do Parque (Entrevista de moradora de Vila Brasil, em julho de 2017).

0 trecho citado relata o início dos conflitos existentes entre a comunidade de Vila Brasil e a administração do Parque Nacional Montanhas do Tumucumaque a respeito da ocupação e do uso do espaço reivindicado pelos agentes em conflito. Entre os moradores de Vila Brasil, apresenta-se um discurso dicotômico quanto à importância do Parque do Tumucumaque para a consolidação da comunidade. Embates locais são desenvolvidos a partir da perspectiva de como o Parque do Tumucumaque pode

7. Nomenclatura utilizada pelos moradores de Vila Brasil para identificação do município de Oiapoque. 
influenciar na vida de seus habitantes. Os moradores que defendem a permanência de Vila Brasil dentro do Parque acreditam que a parceria entre a Associação de Moradores de Vila Brasil e o Governo Federal pode projetar o distrito internacionalmente como um modelo de coexistência entre o homem e o meio-ambiente. Outros acusam os moradores que reivindicam pela integração de Vila Brasil com o Parque do Tumucumaque como pessoas "interessadas em vestir a blusa de guarda do Parque e dizer que é autoridade" (Entrevista concedia por comerciante de Vila Brasil em julho de 2017).

Para Camopi e Vila Brasil, parte dos conflitos sociais são exacerbados pelas condições diferenciadas sobre os dois contextos situacionais de interação entre o "homem" e o "meio-ambiente", elementos centrais para a estratégia retórica desses conflitos. A relação com os parques nacionais é uma das principais disputas que são efetivadas pelos moradores das duas comunidades. Inseridas num contexto internacional de preservação da biodiversidade, cujo objetivo é engendrar mecanismos de proteção e de promoção da Amazônia, Vila Brasil e Camopi passam por situações diferenciadas de manejo do espaço ocupado, tendo em vista a legislação dos países que integram. Cada país, sendo autônomo em suas decisões de como lidar com seus parques nacionais, atribuem normas distintas de preservação e de contato do "homem com a natureza".

Além do contexto ecológico e de luta política ambiental, destacamos que Vila
Brasil e Camopi possuem intensas relações de reciprocidade, que envolvem especialmente a força de trabalho e as relações comerciais (SILVA NETO; LANDIM NETO, 2017). Camopi é abastecida em quase sua totalidade pelos produtos brasileiros. Os serviços como construção de casas e prédios públicos, corte de madeira, caça e a extração de outras matérias primas na floresta são financiados pelo governo francês e construídos com mão de obra brasileira. As duas comunidades possuem intensa interação e densa relação social e econômica, tendo em vista que Camopi não teria outras opções de abastecimento que não aquelas trazidas pelos comerciantes de várias partes do país à Vila Brasil.

Como exemplo da integração de mercado, uma das rotas de compra de vestuário que nos foi relatada em campo em Vila Brasil inicia por Fortaleza, no Ceará, na feira existente na rua José Avelino. 0 comerciante "desce"8 o rio Oiapoque até a "cidade". Depois segue de ônibus a Macapá, onde compra uma passagem de avião para Fortaleza. Quando volta de Fortaleza, com mais de 100 mil reais em mercadorias, segue de ônibus até Belém. Da cidade Lusitânia, continua seu caminho até Macapá por via fluvial, percorrendo o leito do rio Amazonas. Depois contrata uma Picape e chega ao Oiapoque, onde volta de voadeira para Vila Brasil. Segundo o comerciante que relatou rapidamente seu itinerário, o valor de compra de uma peça em Fortaleza de 10 ou 15 reais pode chegar em Vila Brasil a 40 ou 50 euros.

8. Os moradores de Vila Brasil utilizam o termo "descer" para identificar o caminho Vila Brasil-Oiapoque e o termo "subir" para identificar o caminho Oiapoque-Vila Brasil. 
0 modo de socialização entre brasileiros e franceses é caracterizado pela diferenciação de práticas cotidianas, alicerçadas pelas práticas culturais a que pertencem. Modos de vestir, de comer, de trajar, de pensar e de sentir entram em interação nesse contexto, a exemplo das músicas que tocam em Camopi com seus motivos tradicionais e de resgate da "cultura ancestral", enquanto o forró sertanejo alimenta juntamente com o forró eletrônico outras formas de consumo cultural, como em Vila Brasil.

0 modelo de organização política é também influenciado por marcadores de diferença cultural entre os dois lados do rio. Em Camopi, há um prefeito e um conselho; como das demais comunas francesas, Vila Brasil é um distrito de Oiapoque, e sua organização e gestão política se dá atrelada à sede do município, além da Associação de Moradores de Vila Brasil. Esta última se responsabiliza pela limpeza local e pela mobilização dos moradores, uma questão de campo que pretendemos desenvolver em outro texto de antropologia da política.

\section{Trajetórias fronteiriças no garimpo}

A vida em garimpos na Amazônia se destaca a partir da experiência de determinados grupos de pessoas que resolveram migrar de seus locais de origem com o objetivo de conquistar melhores condições movidas por desejos e sonhos de uma boa vida. Principalmente nortistas e nordestinos saíram de suas terras fugindo da seca e da fome com a expectativa de ficarem ricos. A imagem do ser rico é fundamental nesse universo simbólico. Engendraram outras formas de trabalho para além daquelas a que estavam acostumados - especificamente a roça e o gado - para a profissão de garimpeiro, através da qual a "sorte" adquire papel preponderante (BARROZ0, 2017).

Para os garimpeiros, a sorte se avizinha com a possibilidade de achar uma pepita, de bamburrar, ou simplesmente de não ser morto por ter bamburrado. Através da sorte, ganhar dinheiro suficiente para trazer a família para próximo, ou gastar o dinheiro que conseguiu ficando de "porre" e com mulheres, como símbolo de poder masculinistas são dilemas presentes nas expectativas e nos sonhos presentes na vida daqueles que encontraram nos garimpos franco-amapaenses sua forma de experiência sociocultural.

Nesse cenário, os garimpos se configuram como espaços sociais em que novas práticas são incorporadas e redefinidas por atores que advém de várias partes da América Latina e que por vezes não partilham dos mesmos valores morais e culturais. A reconstrução de novas moralidades, alicerçadas em espaços onde regras de convivência apresentam redefinições constantes, propicia que outros modos de lidar com os conflitos sociais sejam entraves para se administrar a vida grupal em garimpos.

0 contato direito com as histórias de vida desses viajantes que percorreram longos caminhos até os garimpos suscita problematizações mais complexas para a própria experiência dos pesquisadores, como também dos próprios sujeitos da pesquisa, tendo em vista que os interlocutores são entrevistados e acabam por recapitular de modo reflexivo suas experiências, confessando-nos, por vezes, terem-no feito pela primeira vez, o que os leva a atribuir novos significados às suas histórias de vida.

São em tais condições que Vila Brasil surge diretamente relacionada à trajetória de vida de migrantes considerados como comerciantes e políticos em Oiapoque. Aqui, como anunciamos anteriormente, 
apresentamos a trajetória de dois homens que chegaram à fronteira ainda na década de 1980, destacando-se, cada um ao seu modo, como pessoas que são ou foram percebidas como "bem-sucedidas" pelo universo simbólico das relações sociais no referido município.

Mauro Maia ${ }^{\bar{a}}$ veio jovem do Ceará para o Amapá, instalando-se primeiramente no Garimpo do Lourenço e um ano após em Oiapoque. Saiu de casa prometendo para a família que só voltaria ao Ceará quando conseguisse se "tornar gente na vida, um homem de bem, dando orgulho a mãe". Sr. Mauro Maia, após alguns anos em Oiapoque, percebeu que a atividade da garimpagem no município se encontrava escassa pela quantidade de migrantes que lá chegavam diariamente.

Quando eu cheguei ao Oiapoque não tinha tanta gente, depois ficou muito. Eram barracas armadas na beira do rio. Uns tinham a sua, outros dividiam. A gente usava ali a bateia, era ir no rio e tirar. 0 garimpo era ali, onde é a orla hoje, na beira do rio. Depois foi ficando mais difícil, não estava aparecendo [ouro] tão fácil. Tinha gente com mais posses que depois trouxe a draga. Você sabe como é, ela puxa tudo. Aí a gente subiu para Vila Brasil (Entrevista com o senhor Mauro Maia, em julho de 2017).

Deslocou-se para Vila Brasil na década de 1980 objetivando menor concorrência e na busca de "garimpos melhores". Observou que na referida comunidade poderia exercer outras atividades laborais para além da garimpagem. Sua percepção está diretamente relacionada aos fluxos migra- tórios, que também trazem consigo uma reformulação local das demandas por serviços, ao ter em vista que a existência de novas necessidades era sempre constante. Vários garimpeiros saiam do garimpo para Vila Brasil em busca de alimentação e também de diversão, o que levou Mauro Maia a mudar de profissão.

Ao observar o referido contexto, adquiriu um lote de terras de 400 hectares, onde hoje possui uma plantação de banana, de açaí e de outras plantas nativas, como também montou um comércio que passou a abastecer aqueles que seguiam para as florestas presentes no território francês como também no território brasileiro. Além disso, observou que os habitantes da cidade de Camopi precisavam de materiais para o abastecimento local.

A trajetória de Mauro Maia está diretamente vinculada a sua militância pela manutenção do distrito de Vila Brasil dentro do Parque Nacional Montanhas do Tumucumaque. Fundador e primeiro presidente da Associação dos Moradores de Vila Brasil, também integrou o conselho de gestão do PNMT. A luta pela manutenção de Vila Brasil é uma das principais ações de Mauro Maia. Apresentando-se como liderança da comunidade, se destaca como principal articulador das demandas por reconhecimento do direito (CARDOSO DE OLIVEIRA, 2011) de não remoção do distrito de Vila Brasil de dentro do Parque Nacional Montanhas do Tumucumaque. Contudo, sua liderança não é hegemônica, tendo de enfrentar várias lutas pela presidência da agremiação. Nestes momentos, se exacerbam os embates entre as facções existentes no distrito, como é

9. Denominaremos as pessoas entrevistadas a partir de nomes fictícios. 
possível observar em sua fala:

No próximo dia 20 de agosto eu vou passar um questionário para todo mundo e vou perguntar quem é a favor e quem é contra o que está acontecendo. Tem que saber quem quer ir embora e quem quer ficar. Todo morador vai ter que dizer se tá do lado deles e a favor do Parque ou se tá do nosso lado e a favor da Vila Brasil! (Discurso proferido por Mauro Maia em julho de 2017)

Seu principal adversário no distrito, o senhor Cabeleira, também foi presidente da Associação dos Moradores de Vila Brasil. Eleito com o apoio do sr. Mauro, distanciou-se da liderança deste após assumir a presidência da agremiação. As disputas situacionais entre as duas lideranças para ser considerado o representante de Vila Brasil acontecem em diversos momentos. Um destes aconteceu enquanto em campo, quando o sr. Cabeleira interpelou um dos pesquisadores:

Você foi na casa do Velho (seu Mauro), mas não foi na minha. Vou contar pra você a minha história, porque a verdade não é do jeito que ele conta não. Ele diz que ele manda aqui porque chegou antes, mas com ele só tá os grandes, os pequenos estão tudo comigo. Como o voto é que conta, na próxima eleição pra presidente de Vila Brasil eu vou ganhar (Conversa com o sr. Cabeleira em julho de 2017).

Exemplificados nas falas acima, destacamos que nos embates políticos locais vários dispositivos são acionados para demarcar as facções inseridas no campo de lutas, ao envolver estratégias de legitimação social, alicerçadas em categorias, como: antiguidade como morador local, representatividade para falar em nome da comunidade junto aos órgãos públicos, autoridade para identificar "os problemas da comunidade" como o alcoolismo, os pequenos furtos e drogas ilícitas, além da disputa por votos para eleger representantes no poder legislativo da cidade de Oiapoque, como também o presidente da Associação de Moradores do Distrito de Vila Brasil.

Insere-se nestes embates apresentados nas falas recorrentes de moradores e principalmente de lideranças a exigência da adesão explícita a uma facção, quando se exige que se diga "quem é a favor do Parque e quem é a favor da Vila Brasil”. Os conflitos e as lutas engendradas por facções políticas caracterizam-se como produto das múltiplas relações sociais que permeiam a vida cotidiana. Em Vila Brasil, estas práticas não são diferentes.

Antonio do Socorro nasceu no Ceará na década de 1950, sem conseguir precisar o ano. Após grave seca, mudou-se ainda criança com a família para o estado do Maranhão, onde viveu a infância, a adolescência e o início da vida adulta. No referido estado, constituiu família e se tornou comerciante, estabelecendo-se segundo suas palavras como "pessoa de grandes posses". Após se apaixonar por uma mulher mais nova, abandona a família e seu comércio e se muda para o Amapá nos anos 1980.

Em Macapá, trabalhou em várias profissões durante alguns anos, a exemplo de motorista e pequeno comerciante, mas não consegue lograr o êxito financeiro similar ao que outrora possuiu. Nos anos de 1990, transfere residência para o Oiapoque com a esposa e uma filha, passando a atuar na busca do ouro em garimpos do Brasil e da Guiana Francesa. Segundo sr. Antonio do Socorro, estar na floresta muitas vezes propicia uma vivência que vai além dos limites estabelecidos entre os dois países. Para o 
ex-garimpeiro, a experiência de estar em um território de outro país muitas vezes não existia, em sua fala nos disse "Olha, eu tava num garimpo pro lado de lá. Mas pra mim não tem isso, é lado de lá, lado de cá... Essa selva ai não tem diferença, é igual a índio aí, não quer saber o que é França e o que é Brasil”. Destarte, estas percepções sobre as fronteiras indicando-as, como apontam Albuquerque e Paiva (2015), como "terra de ninguém" ou como locais isolados sem a “proteção" do Estado servem para aproximá-las da ideia de que são locais violentos ou que determinadas leis adquirem outros dispositivos de interação.

Somado a isso, para o senhor Antonio do Socorro, muitas relações são promovidas a partir de um sentimento de "falta", ao mesmo tempo em que se evidencia momentos de "incertezas" que propiciam limites complexos na vida de garimpos ilegais que ultrapassam o território brasileiro. Isto porque os trabalhadores, como o sr. Antonio, muitas vezes não cumprem os requisitos para se regularizar como migrantes na Guiana Francesa. Esta situação encontra problemas quanto às condições de trabalho, tornando o dia-a-dia no garimpo repleto de tensão, tendo em vista a possibilidade de prisão pelos gendarmens, a polícia francesa. Relato deste exemplo se dá nas falas do sr. Antonio do Socorro, quando relata como se desenrola a atuação do referido grupo policial francês:

Uma vez, quando a gente viu, tinha francês pra todo lado, pra tudo que é canto. Aí só dava pra correr. Deixei tudo pra trás, não levei nada. Todo o material... Quando esses franceses pegam a gente, tem uns que são civilizados, só prendem. Uns mandam pro presídio, tem vezes que mandam a gente de volta pro Brasil. Mas tem uns que gostam de atirar, de bater.
0 pessoal diz que se fosse nos Estados Unidos tava todo mundo morto, mas pra eles a gente diz que só veio trabalhar. (Entrevista com um garimpeiro em março de 2017).

Como relata o senhor Antonio, se as leis de cada país são adversas ao momento situacional vivenciado pelos garimpeiros, não significa que nos garimpos não existam regras e que estas não devam ser seguidas. Pelo contrário, cada garimpo pode despontar códigos e normas que devem ser administrados e partilhados pele diversidade de trabalhadores que neles existem, independentemente da mobilidade.

Assim, os códigos morais nos garimpos podem variar de garimpo para garimpo, e as práticas punitivas também. Para Antonio do Socorro, entre as décadas de 1980 e 1990, a presença do Estado brasileiro era menor do que a existente hoje, corroborando para que as decisões de penas fossem julgadas e aplicadas sem um processo convencional de defesa. Neste contexto, mortes e roubos em garimpos se constituíam como práticas comuns, mas que, se descobertas, poderiam ocasionar conflitos a serem administrados entre os próprios garimpeiros.

\section{Considerações finais}

Neste artigo, discutimos as possibilidades de inserção social promovidas por fluxos que destacam o ouro e o Euro como dispositivos produtores de suas agências. Dialoga assim com a terceira margem, categoria que refuta a vida ordinária para inserir novos processos de obtenção de ganhos a partir de investimentos. Os investimentos não se vinculam apenas ao valor econômico, mas principalmente a processos sociais que estão estritamente vinculados à superação pelo trabalho, como também carac- 
terizados pela sorte. Para tanto, dominar os percursos promovidos pelos garimpeiros resulta na formulação de novas forças e novas configurações do real. 0 sonho do garimpo se torna, neste sentido, objeto de ascensão, promovendo para muitos uma mudança de profissão.

Aquele que ascende como garimpeiro advém de incursões para um universo de profissões que não se descocam da estrutura de funcionamento do garimpo. Ex-garimpeiros se tornam pirateiros, marreteiros, comerciantes, dentre outros, que desfrutam sua posição a partir das mobilidades acionadas pela existência do universo categorial das trocas e negociatas produzidas pela extração do ouro, utilizando muitas vezes as redes costuradas enquanto garimpeiros para o funcionamento de seus novos empreendimentos.

Parte destas questões apresenta que as fronteiras vão além de uma divisão territorial, mas que empregam novos costumes no contexto em tela. Assim, o comércio assume um papel preponderante para se entender como flui a economia do garimpo, que hoje, em Oiapoque e em Vila Brasil, divide espaço com o Euro. A referida moeda, que possui poder de compra quatro vezes maior do que o Real, propicia novos arranjos econômicos e sociais entre os habitantes fronteiriços.

Destarte, a história de vida de ex-garimpeiros que adquiriram novos espaços nas engrenagens do garimpo demonstra as modificações e permanências de situações de vida, normas e regras estabelecidas numa terceira margem, que está distante daquela pertencente ao Brasil, como também à França.

\section{Referências bibliográficas}

ALBUQUERQUE, J. L. A dinâmica das fronteiras: deslocamento e circulação dos "brasiguaios" entre os limites nacionais. In: Horizontes antropológicos, Porto Alegre, v.15, n 31, p.137-166, 2009.

ALBUQUERQUE, J. L.; PAIVA, L. F. S. Entre nações e legislações: algumas práticas de "legalidade" e "ilegalidade" na tríplice fronteira amazônica (Brasil, Colômbia, Peru).In: Revista Ambivalências, V.3, N.5, p. 115 - 148, Jan-Jun/2015.

ALICINO, R. Clevelândia do Norte. Guanabara: Editora do Exército Editora, 1971.

ANDRADE, R. F. Malária e migração no Amapá: projeção espacial num contexto de crescimento populacional. Núcleo de Altos Estudos Amazônicos. Universidade Federal do Pará, 2008.

AQUINO, J. P. D.; VARGAS, J. Criminalidade e Segurança Pública na fronteira do Brasil com a Guiana Francesa. In: BARREIRA, César; TAVARES DOS SANTOS, José Vicente. (Org.). Paradoxos da Segurança Cidadã. Porto Alegre: TOMO Editorial, 2016, v. 1, p. 89-102.

BARROZO, J. C. Mobilidade social no garimpo: herança ou esforço pessoal. In: Novos Cadernos NAEA. v. 20, n. 1, p. 135-151, jan-abr 2017.

BECKER, H. S. Falando da sociedade: ensaios sobre as diferentes maneiras de representar o social. Rio de Janeiro: Zahar, 2009.

BRASIL. Lei $\mathrm{n}^{\circ} \mathbf{9 . 9 8 5}$ de 18 de Julho de 2000. Regulamenta o art. 225, § $1^{\circ}$ incisos I, II, III e VII da Constituição Federal, institui o Sistema Nacional de Unidades de Conservação da Natureza e dá outras Providências. Brasília, DF: 18 jul. 2000. Disponivel em: <http://www.planalto.gov.br/ccivil/leis/L9985.htm>. Acesso em: 8 ago. 2017.

BOURDIEU, P. L'Illusion biographique. Actes de la Recherche en Sciences Sociales, [s. l.], v. 62/63, p. 69-72, juin, 1986.

BOURDIEU, P. Marginalia: algumas notas adicionais sobre o dom. In: Mana, 2(2), 7-20, 1996. 
BOURDIEU, P. Razões práticas: sobre a teoria da ação. Tradução Mariza Corrêa. 11. ed. Campinas: Papirus, 2008.

LEFORT, C. “A troca e a luta dos homens”. In: LEFORT, C. As formas da história: ensaios de antropologia política. São Paulo: Brasiliense, 1979.

MARTINS, J. S. Fronteira: a degradação do Outro nos confins do mundo, 2. ed. São Paulo: Contexto, 2014.

OLIVEIRA, L. R. C. Direito legal e insulto moral: dilemas de cidadania no Brasil, Quebec e EUA. 2. ed. Rio de Janeiro: Garamond, 2011.

PAIVA, L. F. S. As dinâmicas do monopólio da violência e do controle em um território transfronteiriço amazônico. Revista Tempo da Ciência, Toledo, v. 23, n. 46, p. 60-79, julho/dez, 2016.

PAIVA, L. F. S. Nas margens do Estado-nação: as falas da violência na tríplice fronteira amazônica, TOMO (UFS), n.27, julho/dezembro, p.327-359, 2015.

PALHARES, J. M. Educação ambiental e sustentabilidade: o caso de Vila Brasil no município de Oiapoque Amapá-Brasil. In: REDE - Revista Eletrônica do PRODEMA, v. 10, n. 2, 2016, p. 108-119.

OLIVEIRA FILHO, J. P. 0 caboclo e o brabo: notas sobre duas modalidades de força de trabalho na expansão da fronteira amazônica no século XIX. In: Encontros Com a Civilização Brasileira, Rio de Janeiro, v. 11, p. 101-140, 1979.

RABOSSI, F. Tempo e movimento em um mercado de fronteira: Ciudad del Este, Paraguai. In: Sociologia \&t Antropologia | Rio de Janeiro, v.05.01: 405 - 434, agosto, 2015.

ROMANI, C. Um eldorado fora de época. A exploração dos recursos naturais no Amapá. In: Revista Projeto História, São Paulo, n. 42, p.271 - 302, jun. 2011.

ROSA, J. G. “A terceira margem do rio”. In: ROSA, J. G. Ficção completa, volume II. Rio de Janeiro: Nova Aguilar, 1994.
SENNETT, R. 0 artífice, 5.ed. Rio de Janeiro: Record, 2015.

SILVA, G. V. Usos Contemporâneos da fronteira franco-brasileira: entre os ditames globais e a articulação local. 1. ed. Macapá: UNIFAP, 2014.

SILVA, J. M. Amazônia em contexto: uma perspectiva antropológica. Curitiba: CRV, 2016.

SILVA NETO, A. S.; LANDIM NETO, F. 0. Conflitos socioambientais entre a comunidade da sede distrital de Vila Brasil, Oiapoque - Amapá e o Parque Nacional Montanhas do Tumucumaque. In: REDE: Revista Eletrônica do PRODEMA, v. 11, p. 57-67, 2017.

SOARES, C.; CHELALA, C. O Caso de Vila Brasil no Parque Nacional Montanhas do Tumucumaque. In: PRACS: Revista Eletrônica de Humanidades do Curso de Ciências Sociais da UNIFAP, No 2. Dez. 2009.

VELHO, 0. Frentes de expansão e estrutura agrária. Rio de Janeiro: ZAHAR ED., 1972.

WEBER, M. Economia e sociedade. Brasília: Editora Universidade de Brasília,1994. 2 v. 
RESUMO

Este artigo discute as formas da experiência social na fronteira franco-brasileira. A partir da ideia heurística de terceira margem, pensa a fronteira como lugar de deslocamentos e tensões. Baseado em trabalho de campo etnográfico, descreve e analisa as atividades de garimpagem e comércio do ponto de vista dos atores sociais. 0 objetivo é realizar uma primeira aproximação do campo, discutindo fronteira como ferramenta analítica. Percebe-se como principal conclusão que as dimensões morais e simbólicas estão conectadas com as atividades propriamente socioeconômicas, que a vida social na fronteira franco-brasileira exige uma abordagem de suas múltiplas realidades.

\section{PALAVRAS-CHAVES}

Amapá. Guiana Francesa. Fronteira franco-brasileira. Garimpo. Comércio.

\section{ABSTRACT}

This article discusses the forms of social experience on the Franco-Brazilian frontier. From the third-margin heuristic idea, it thinks of the frontier as a place of displacements and tensions. Based on ethnographic fieldwork, it describes and analyzes the activities of garment and trade from the standpoint of social actors. The objective is to make a first approximation of the field, discussing frontier as an analytical tool. It is perceived as the main conclusion that the moral and symbolic dimensions are connected with the activities properly socioeconomic, that the social life in the French-Brazilian border requires an approach of its multiple realities.

\section{KEYWORDS}

Amapá. French Guiana. French-Brazilian border. Mining. Trade. 